\title{
HMGA2 overexpression is associated with differential expression of miRNAs in uterine leiomyomas
}

\author{
Julia BH Mello ${ }^{1,2^{*}}$, Mateus C Barros-Filho ${ }^{2}$, Priscila Ramos Cirilo ${ }^{1}$, Fábio A Marchi ${ }^{2}$, Anagloria Pontes ${ }^{3}$, \\ Silvia R Rogatto 2,3
}

From São Paulo Advanced School of Comparative Oncology

Águas de São Pedro, Brazil. 30 September - 6 October 2012

\section{Background}

Uterine leiomyomas (UL) are mesenchymal benign tumors extremely common that represent a significant public health problem. The deregulation of growth factors and microRNAs (miRNAs), shortening of telomeres, excessive production of disorganized extracellular matrix, loss of heterozygosity and recurrent chromosomal aberrations (including $7 \mathrm{q} 22$ deletion and chromossomal rearrangements in 12q15) have been suggested to contribute to the growth of fibroids. HMGA2, mapped to $12 \mathrm{q} 15$, is a major regulator of benign tumorigenesis from mesenchyme-derived tissues and stem-cell self-renewal. In UL, HMGA2 overexpression is frequently reported. Recently it has been shown that repression of HMGA2 by microRNA let-7s is a critical molecular regulatory mechanism associated with tumor growth. In this study, it was evaluated three miRNAs mapped to 7q22 (miR-25, miR-93 and miR-106b) and miR-let-7a (previously reported as $H M G A 2$ regulator). These findings were compared with gene expression microarray data.

\section{Patients and methods}

Seventy-eight fresh frozen UL and 20 adjacent normal myometrium (MM) were collected from 54 patients who had undergone a hysterectomy procedure. Paired analysis were performed in 20 cases. Quantitative real time RTPCR was applied to evaluate the expression of miR-let7a, miR-25, miR-93, and miR-106b using RNU44, RNU48 and U47 as endogenous control. Array CGH and expression analysis was carried out using Agilent $4 \times 44 \mathrm{k}$ arrays in the same set of cases.

\section{Results}

Losses of 7q22 were significantly detected in UL by array CGH. In 7q22 is mapped the miR-93 and miR-106b which were found as down-regulated $(\mathrm{p}<0.001 ; \mathrm{p}=0.001$, respectively). miR let-7a was also down-regulated $(\mathrm{p}=0.001)$. Oligorrays expression analysis confirmed HMGA2 overexpression.

\section{Conclusions}

Losses of 7q22 were associated with miR-93 and miR-106b downexpression leading to deregulation of target genes involved in ULs pathogenesis. In addition to miR-let7a, miR-93 is also a candidate for HMGA2 regulation in these tumors.

\section{Financial support \\ FAPESP and CNPq.}

\section{Author details}

${ }^{1}$ Institute of Biosciences, UNESP, Botucatu, SP, Brazil. ${ }^{2} \mathrm{CIPE}$ - AC Camargo Cancer Hospital, São Paulo, SP, Brazil. ${ }^{3}$ Faculty of Medicine, UNESP, Botucatu, SP, Brazil.

Published: 4 April 2013

doi:10.1186/1753-6561-7-S2-P36

Cite this article as: Mello et al: HMGA2 overexpression is associated with differential expression of miRNAs in uterine leiomyomas. $B M C$ Proceedings 2013 7(Suppl 2):P36.

* Correspondence: juliahmello@gmail.com

'Institute of Biosciences, UNESP, Botucatu, SP, Brazil

Full list of author information is available at the end of the article

(c) 2013 Mello et al; licensee BioMed Central Ltd. This is an Open Access article distributed under the terms of the Creative Commons 